\title{
The Intramural Pouch in the Duodenum of the Indian Elephant: A Macro- and Microscopic Study of Six Cases
}

\author{
By

\section{Toshiro Kamiya} \\ Department of Anatomy, University of Tokyo School of Medicine, Tokyo \\ (Director: Prof. Hiroshi Hosokawa)
}

\section{Tsuneo Fujita}

Department of Anatomy, University of Okayama School of Medicine, Okayama

(Director: Prof. Hiromu Outi)

As Aristotle already knew, the elephant has no gall bladder. Instead, in the duodenum of this animal $\mathrm{C}$ a $\mathrm{m}$ p e r $(1774,1802)$ found a large intramural pouch which connects with the bile and pancreatic ducts on the one hand and, on the other, opens into the duodenal canal with a big papilla. A brief macroscopic description of this pouch was later made by $\mathrm{O}$ wen (1868) and by $\mathrm{Miall}$ and $\mathrm{Green}$ w o o d (1878).

Several years ago we had an opportunity to dissect a female Indian elephant ( $\mathrm{S} \mathrm{himizu}$ et al. 1960) and the macro- as well as microscopic structure of the duodenal pouch was examined. The interior of the pouch was equipped with large folds which were covered with a thick layer of tubulo-alveolar glands. It was thus concluded that the organ represented not only a cavity to pool the bile and pancreatic juices as hitherto believed, but also a gland of active secretion.

Our findings on the position of the sphincter muscles of the pouch differed considerably from that of previous authors. $\mathrm{O}$ w e $\mathrm{n}$. (1868) and Miall and Green.w o od (1878) recognized a sphincter in the duodenal papilla, while we found one at the pouring site of the pancreatic duct and another at that of the bile duct; the papilla was supplied with no sphincter muscle. Furthermore a problem remained, as we found no accessory pancreatic duct in spite of the existence of an accessory papilla. These problems seemed to be 
settled only through observation of further cases. Microscopic observation of the pouch, performed in the above mentioned work of ours for the first time, was partly unsatisfactory because of considerable postmortal changes in the tissues. For instance, we could not decide whether the glands in the pouch were mucous or serous.

In the course of the following six years we could examine the organ in question in five more cases of the Indian elephant, some of which were preserved in good histological condition. In the present report we would like to sum up our findings thus obtained in all six animals. Discussion will also be made on the comparative as well as functional anatomy of the duodenal pouch.

\section{Material and Methods}

The animals used in this work were 3 young and 3 infant female Indian elephants, the detailed data of which are shown in Table 1. In four cases organs in situ were observed carefully and then were cut out to be dipped in $10 \%$ formalin for further detailed dissection. In two cases (Case 2 and 3), however, only the fixed organs, i.e. the pouch and its associated structures, were provided for our use.

Table 1. Data of the animals examined.

\begin{tabular}{|c|c|c|c|c|c|c|}
\hline Case & Sex & Age & Body weight & $\begin{array}{c}\text { Shoulder } \\
\text { height }\end{array}$ & Liver weight & $\begin{array}{c}\text { Pancreas } \\
\text { weight }\end{array}$ \\
\hline No. 1 & F & 7 or $8 \mathrm{yr}$. & $1,500 \mathrm{~kg}$ & $185 \mathrm{~cm}$ & $10.6 \mathrm{~kg}$ & $400 \mathrm{gr}$ \\
No. 2 & $\mathrm{~F}$ & $5 \mathrm{yr}$. & - & - & - & - \\
No. 3 & $\mathrm{~F}$ & $5 \mathrm{yr}$. & - & $135 \mathrm{~cm}$ & $5.1 \mathrm{~kg}$ & - \\
No. 4 & $\mathrm{~F}$ & $1 \mathrm{yr}$. & $110 \mathrm{~kg}$ & $84 \mathrm{~cm}$ & $3.0 \mathrm{~kg}$ & $100 \mathrm{gr}$ \\
No. 5 & $\mathrm{F}$ & $9 \mathrm{mon}$. & $68 \mathrm{~kg}$ & $60 \mathrm{~cm}$ & $1.9 \mathrm{~kg}$ & - \\
No. 6 & $\mathrm{~F}$ & $5 \mathrm{mon}$. & $82 \mathrm{~kg}$ & - & $1.2 \mathrm{~kg}$ & - \\
\hline
\end{tabular}

Some of the pouches, after formalin fixation, were cut in various directions to see the structure of their wall; others were dissected from outside layer by layer in order to elucidate the muscular architecture of the wall. Besides the pouch, dissection was made also in its associated organs, i.e. the liver, pancreas and duodenum. The whole extent of the pancreatic ducts was dissected out in 3 cases, removing the parenchyme of the pancreas.

For histological investigation small parts of the material were cut out before the macroscopic dissection and fixed in $10 \%$ formalin 
or Bouin's solution. The paraffine (partly celloidin) sections were stained with hematoxylin-eosin, Masson-Goldner's trichrome and aldehyde-fuchsin (counter-staining with Masson-Goldner). Some sections were treated with PAS reaction.

\section{Observations}

1. The external aspect of the duodenal pouch (Fig. 1).

The pouch lies in the cranial wall of the duodenum $(75 \mathrm{~cm}$ anal to the pylorus in Case 1 and $60 \mathrm{~cm}$ in Case 2). It is hidden intramurally but easily noticeable from outside by the ovoid elevation of the surface. The long axis $(9 \mathrm{~cm}$ in Case 1$)$ of the pouch is laid obliquely from the dorso-oral to ventro-anal direction. The dimensions of the pouch in every case are shown in Table 2.

Table 2. Dimensions of the duodenal pouch and papillae duodeni.

\begin{tabular}{|c|c|c|c|c|c|c|c|c|}
\hline \multirow[b]{2}{*}{ Case } & \multicolumn{2}{|c|}{ Duodenal pouch } & \multicolumn{3}{|c|}{ Main papilla } & \multicolumn{3}{|c|}{ Accessory papilla } \\
\hline & length & width & $\begin{array}{l}\text { base } \\
\text { diameter }\end{array}$ & height & $\begin{array}{c}\text { orifice } \\
\text { bore }\end{array}$ & $\begin{array}{c}\text { base } \\
\text { diameter }\end{array}$ & height & $\begin{array}{c}\text { orifice } \\
\text { bore }\end{array}$ \\
\hline No. 1 & $9.0 \mathrm{~cm}$ & $6.0 \mathrm{~cm}$ & $4.5 \mathrm{~cm}$ & $2.5 \mathrm{~cm}$ & $1.0 \mathrm{~cm}$ & $2.0 \mathrm{~cm}$ & $1.5 \mathrm{~cm}$ & $0.3 \mathrm{~cm}$ \\
\hline No. 2 & $8.3 \mathrm{~cm}$ & $4.5 \mathrm{~cm}$ & $2.4 \mathrm{~cm}$ & $1.5 \mathrm{~cm}$ & $0.6 \mathrm{~cm}$ & $1.2 \mathrm{~cm}$ & $0.6 \mathrm{~cm}$ & $0.3 \mathrm{~cm}$ \\
\hline No. 3 & $9.0 \mathrm{~cm}$ & $5.0 \mathrm{~cm}$ & $2.5 \mathrm{~cm}$ & $1.4 \mathrm{~cm}$ & $0.4 \mathrm{~cm}$ & - & - & - \\
\hline No. 4 & $4.0 \mathrm{~cm}$ & $2.5 \mathrm{~cm}$ & $1.3 \mathrm{~cm}$ & $0.7 \mathrm{~cm}$ & - & - & - & - \\
\hline No. 5 & $4.8 \mathrm{~cm}$ & $2.8 \mathrm{~cm}$ & $1.6 \mathrm{~cm}$ & $0.9 \mathrm{~cm}$ & $0.5 \mathrm{~cm}$ & 一 & - & - \\
\hline No. 6 & $2.6 \mathrm{~cm}$ & $1.6 \mathrm{~cm}$ & $1.1 \mathrm{~cm}$ & $0.8 \mathrm{~cm}$ & $1.5 \mathrm{~cm}$ & $0.7 \mathrm{~cm}$ & $0.3 \mathrm{~cm}$ & $0.1 \mathrm{~cm}$ \\
\hline
\end{tabular}

In its dorso-oral end the pouch is connected with the bile and pancreatic ducts. The bile duct $(5 \mathrm{~cm}$ long and $2 \mathrm{~cm}$ thick in Case 1), deriving from between the right and left central lobes of the liver, near the caudal margin of the organ, reaches the pouch on the oral side of the pancreatic duct. It has a very thick and hard wall with a massive smooth muscle layer whose fibres run mainly circularly. The pancreatic duct ( $8 \mathrm{~mm}$ thick in Case 1$)$, on the contrary, has a thin and elastic wall.

2. View from the duodenal interior (Fig. 2).

Seen from the interior of the duodenum, the intramural pouch scarcely makes an elevation on the mucous surface, except for its ventro-anal end which forms a large cone-like papilla duodeni. The orifice of the pouch opens at the top of the cone. 


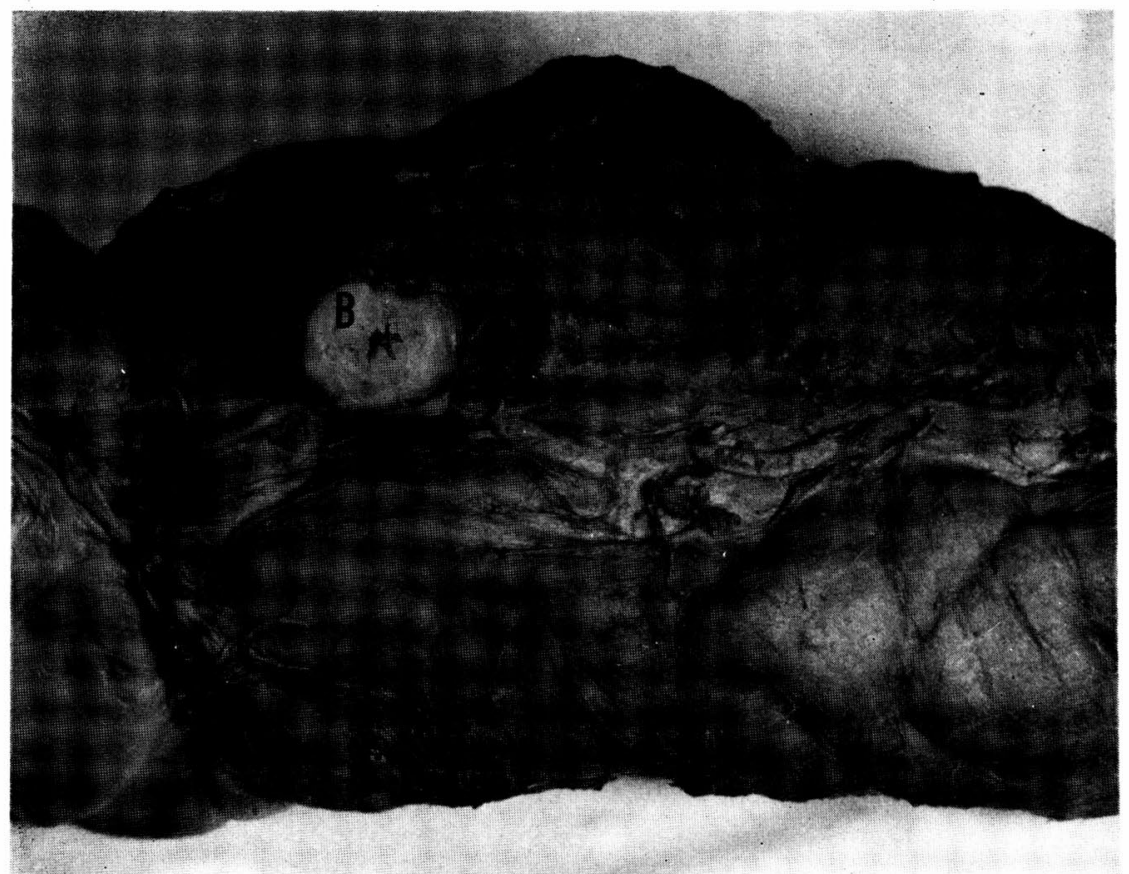

Fig. 1. Outside view of the intramural pouch of the duodenum. 7-year-old Indian elephant (Case 1). The bile (B) and pancreatic (P) ducts are cut; $\times 2 / 3$.

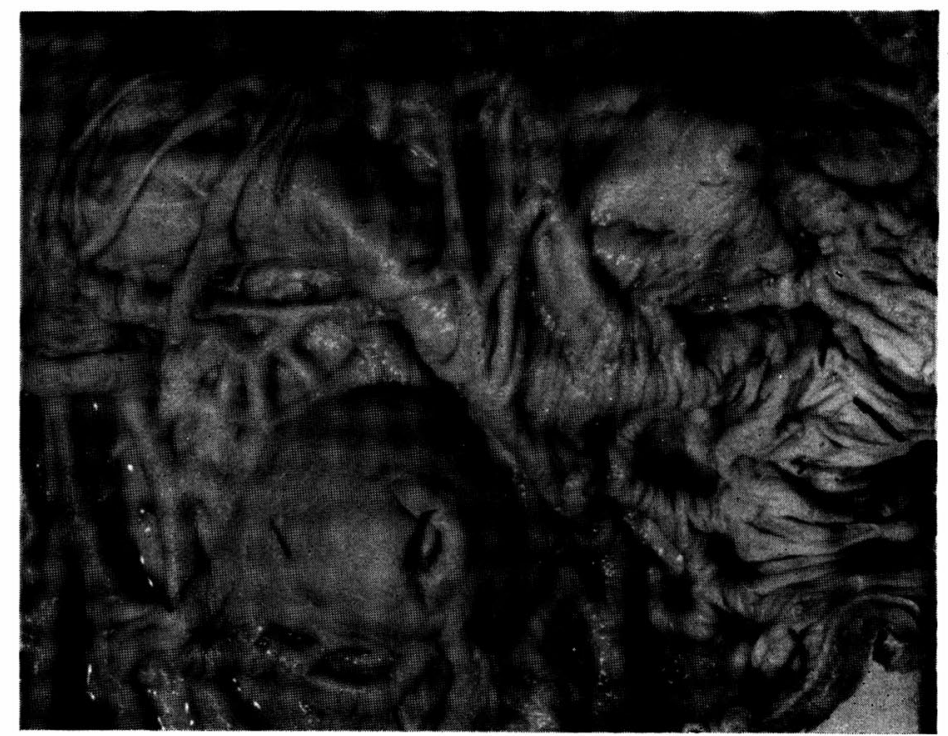

Fig. 2. Surface of the duodenal mucosa. Note the big duodenal papilla (below left) and the small accessory papilla (upper right). Case $1 ; \times 2 / 3$. 
Not far from this papilla, dorso-anal to it, one finds the second or accessory papilla which, though smaller, is similar in shape to the former. The dimensions of both papillae are shown in Table 2.

3. Observations on the rouch cut in sections (Fig. 3, 4).

Beneath the covering of the serous membrane of the duodenum the pouch has well-developed musculature which can be divided into 4 layers. From outside inwards, there are two oblique muscle layers,

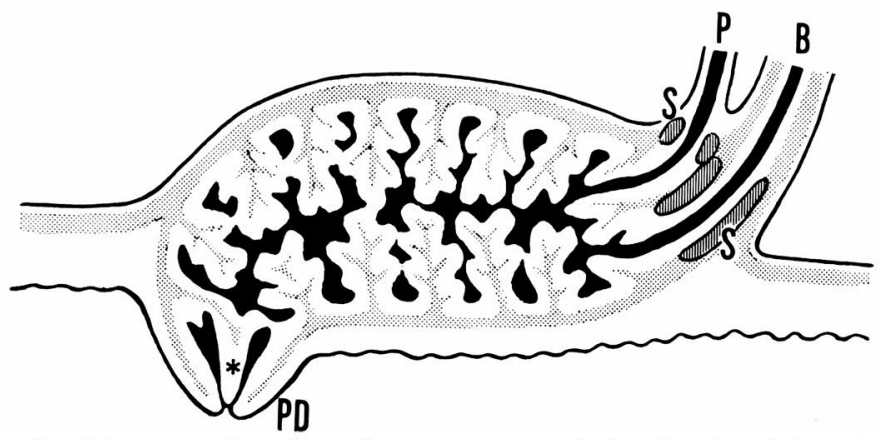

Fig. 3. Diagram showing the structure of the duodenal pouch. The bile (B) and pancreatic (P) ducts are provided with shincters (S). The papilla duodeni $(\mathrm{PD})$ has a plug-like fold $(*)$ in its orifice. The musculature is shown gray.

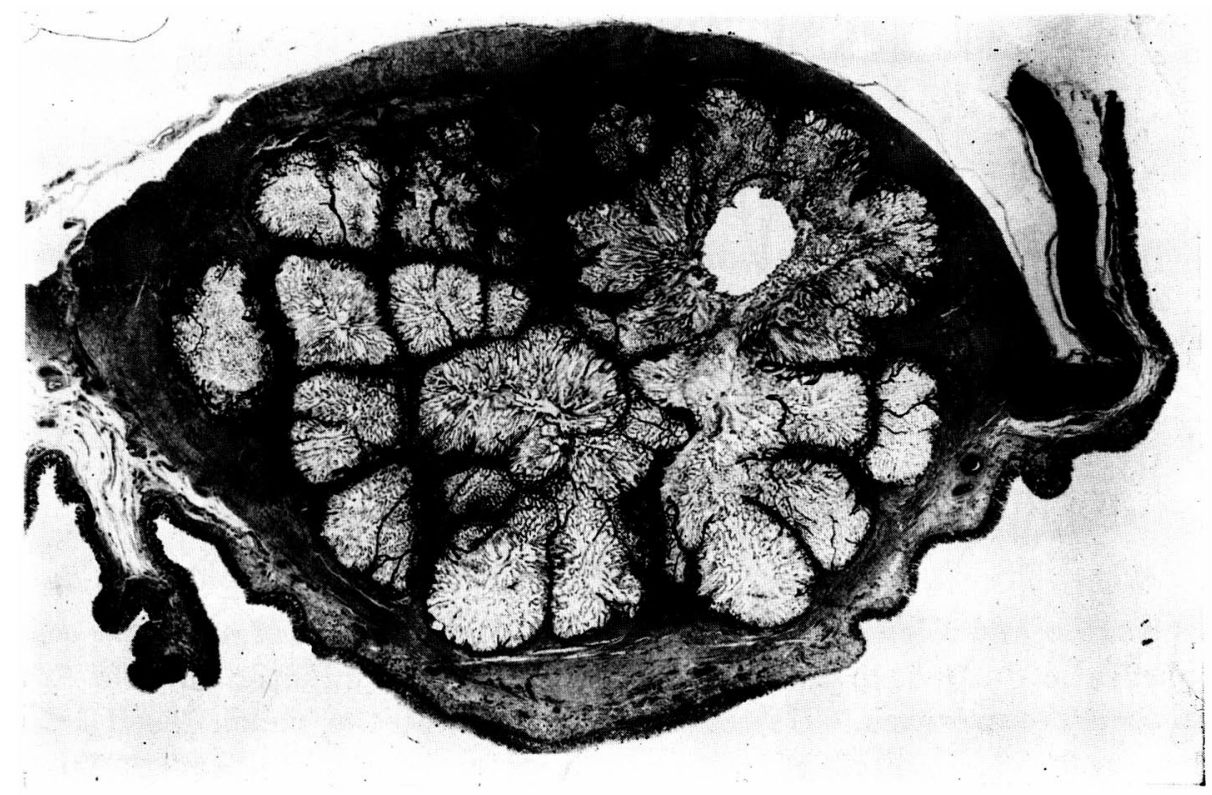

Fig. 4. Duodenal pouch of a 1-year-old Indian elephant (Case 4 ) in cross celloidin-section, stained with hematoxylin-eosin; $\times 4$. 
Fig. 5. Dissection of the muscular layers of the pouch in a 5-year-old Indian elephant (Case 2).

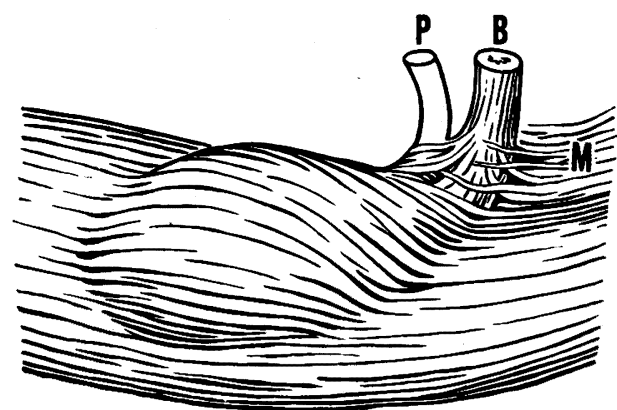

$\leftarrow$ anal

(1) ventral
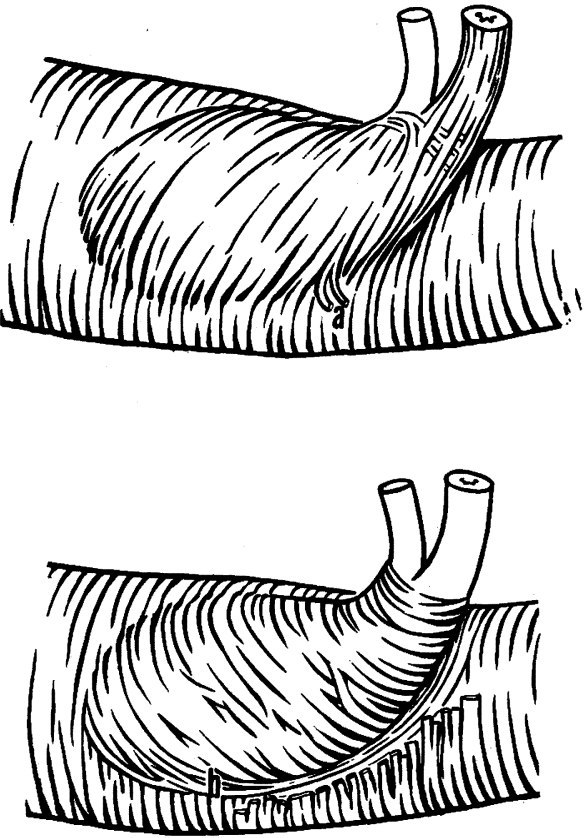

5-1. The outermost layer corresponding to the longitudinal musculature of the duodenum. B: bile duct, $\mathrm{P}$ : pancreatic duct, $\mathrm{M}$ : a thin muscular layer in the lesser omentum.

5-2. The second, oblique muscle layer connected with the circular musculature of the duodenum. a: Muscle bundles joining the longitudinal musculature of the duodenum.

5-3. The third or circular layer. b : Muscle bundles running along the curvature of the pouch to be connected with the circular musculature of the duodenum.

a circular and a longitudinal layer. At the openings of the bile and pancreatic ducts into the pouch a conspicuous sphincter muscle can be seen around each. However, the oriffice of the pouch itself into the duodenum is supplied with no sphincter, a finding different from that of previous authors who described a sphincter there (cf.: Introduction). 


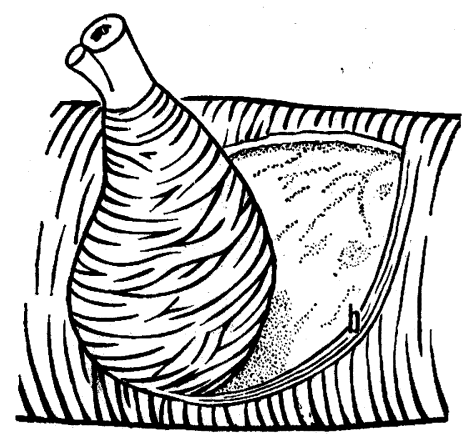

5-4. The pouch with its circular muscle layer is raised up. A fascia-like tissue corresponding to the submucosa of the duodenum is seen in the bottom of the pouch.

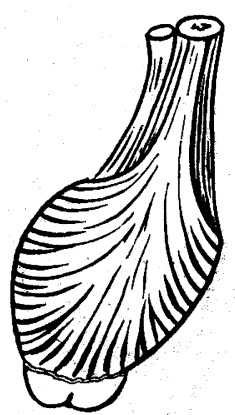

5-5. The fourth or innermost layer. The pouch is dissected out from the wall of the duodenum.

The inside of the pouch is rich in large folds which run mainly circularly and incompletely separate the interior into many compartments. One of the folds is inserted with its tip into the orifice of the pouch (Fig. 2, 3). Each fold consists of a muscular plate extending inwards from the innermost layer of the pouch musculature and of a soft white glandular mass covering it. The lumen of the pouch is filled with yellowish (greenish in formalin fixed specimen) mucous fluid.

4. Dissection of the muscular layers of the pouch (Fig. 5, 6).

The relations between the four muscle layers described above are treated here in more detail, based mainly upon our findings in Case 2, the musculature of which was dissected layer by layer.

1) The first or outermost layer is nothing but the longitudinal muscle fibres of the duodenum running over the swelling of the pouch, obliquely to its axis. At the juncture with the bile duct a few of the fibres turn to join its longitudinal muscle (Fig. 5-1).

2) The fibers of the second muscle layer are the continuation of the circular musculature of the duodenum, except for a very small part of the fibers bending at the ventral margin of the pouch to flow into the longitudinal muscular layer of the duodenum (Fig. 5-2).

3) The third layer is the ring musculature proper to the pouch. In the dorsal curvature the muscle fibres are continuous with the circular musculature of the duodenum, while in the ventral curvature they run deep into the floor of the pouch to circumscribe it completely, except for a few of them which curve along the ventral curvature to join the circular musculature of the duodenum. The sphincters 


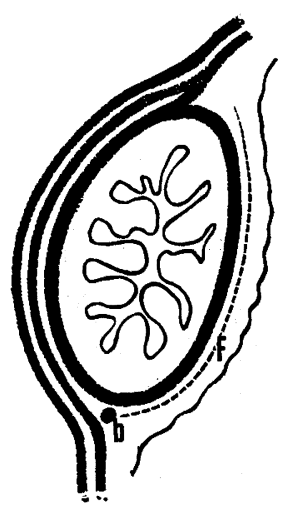

Fig. 6. Diagram showing the relation of muscular layers in cross section of the pouch. The innermost (fourth) layer is omitted. b: The connecting muscle bundle shown in Fig. 5-3. F: fascia-like tissue. of the pancreatic and bile ducts, which belong to this muscle layer, are not so conspicuously shown in this way of dissection as in observation of sections (Fig. 5-3, 5-4).

4) The innermost layer comprises the fibres which are extensions of the longitudinal fibres of the bile and pancreatic ducts. It runs longitudinally through the pouch wall down to the duodenal papilla, extending in its course thin processes or branches into each fold of the pouch. Some of the fibres of this layer diverge to join the third or circular layer (Fig. 5-5).

5. Microscopic observation of the pouch (Fig. 7).

1) Mucosa: The thick lamina propria is filled with well-developed tubulo-alveolar glands. The upper $3 / 4$ to $4 / 5$ of each gland corresponds to the tubular part, the cells of which are cylindrical and mingled with some goblet cells. The remaining alveolar part of the gland comprises cells with round nuclei shifted far to the basal part of the cell. The cytoplasm of these cells is strongly stained with aldehyde-fuchsin and intensely positive in PAS reaction. These mucous glands of the pouch resemble very closely those of the duodenum and it is difficult to discriminate between them. Furthermore, the walls of the bile and pancreatic ducts contain similar glands, though they are much less developed.

In the loose connective tissue between the glands, small aggregations of lymphocytes are recognized here and there.

2) Submucosa: The lamina muscularis mucosae is lacking. In the narrow space between the bottom of the gland and the muscular layer, one can find groups of nerve cells which may correspond to the ganglia of Meissner.

3) Muscular layer: The layer of smooth musculature of the pouch is considerably thick. The muscle fibres, branching from this layer, proceed into the folds of the pouch, thus forming the septa of the glands.

The connective tissue among the muscle fibres is rich in blood vessels and nerves Aggregations of nerve cells which may corres- 


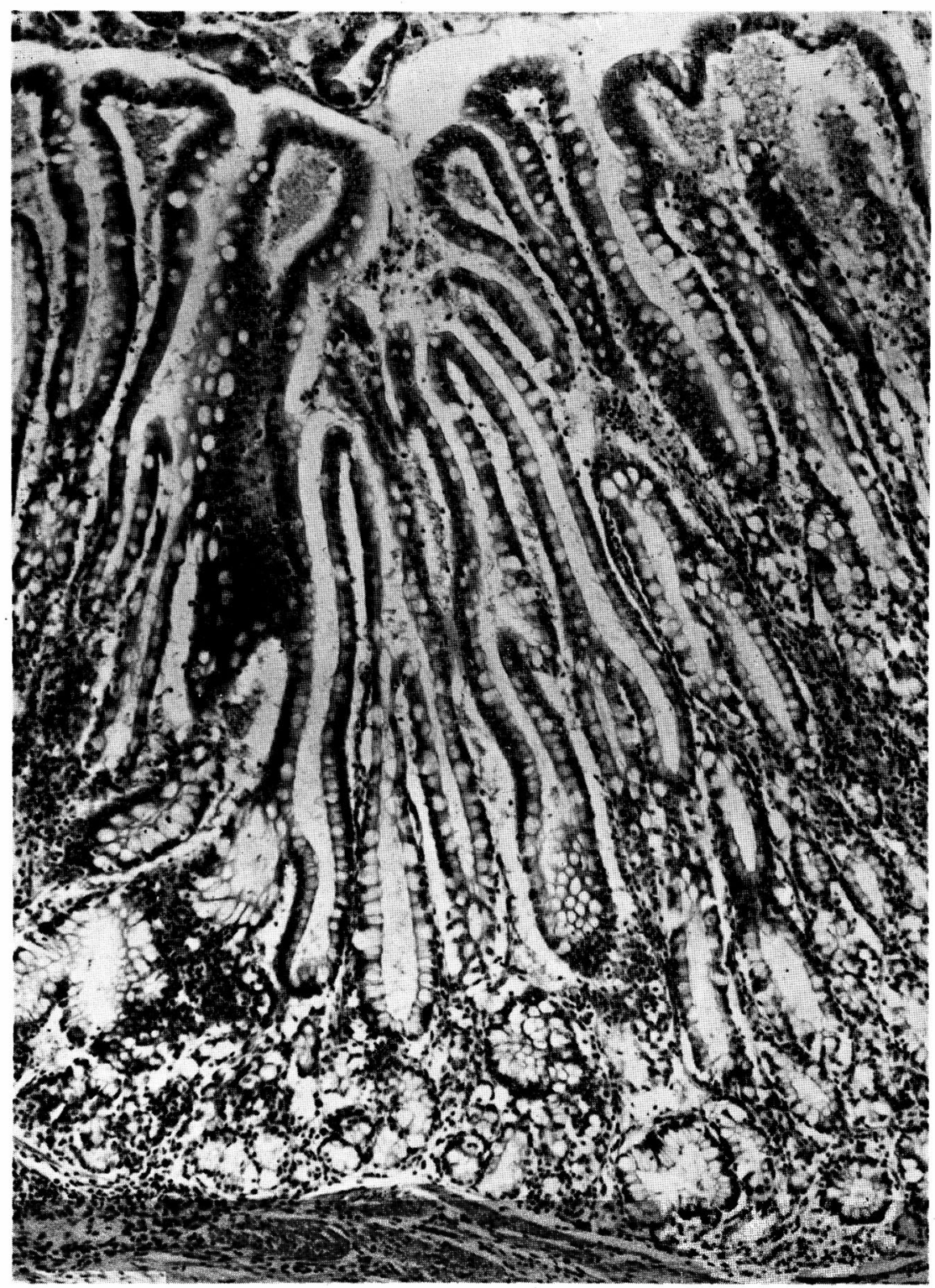

Fig. 7. Microphotograph of the duodenal pouch in a 1-year-old Indian elephant (Case 4). The whole thickness of the glandular layer and a small portion of the muscular layer (below) are seen. Paraffine section stained with hematoxylin-eosin; $\times 150$. 
pond to the ganglia of Auerbach are recognized here and there.

The muscular layer is covered by a thin tunica subserosa and by the tunica serosa or peritoneum. The floor or intestinal side of the pouch is continuous with the fascia-like submucosal connective tissue of the duodenum which is rich in blood vessels, nerves and ganglia.

6. Accessory papilla and accessory pansrea'ic duct (Fig. 2, 8).

In the accessory papilla of the duodenum there is a small space rich in folds. The microscopic structure of this space is similar to that of the main pouch described above. Although no accessory pancreatic duct was found in the first case (cf. Introduction), we could recognize it in all other cases in connection with the accessory papilla.

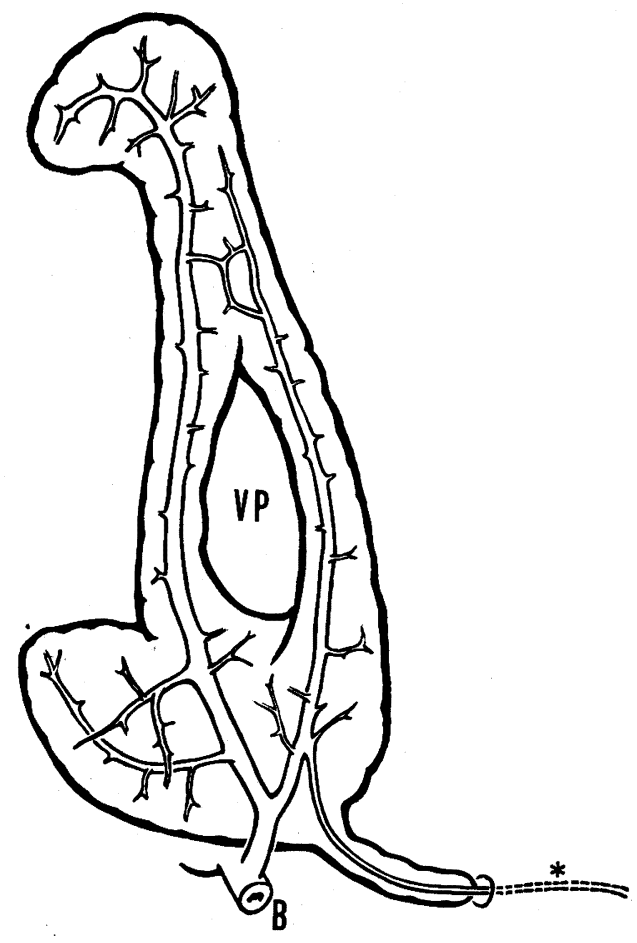

Fig. 8. An example of the distribution of the duct-system within the pancreas. Dissection in a 1-year-old Indian elephant (Case 4). Ventral view. B : bile duct. VP: hole of the pancreas for the passage of the portal vein. * Intramural part of the accessory pancreatic duct running towards the accessory papilla. 


\section{Discussion}

1. Comparative anatomy of the duodenal pouch.

In various mammals, including man, the terminal portion of the bile duct is ampullated and a greater or lesser amount of glandular structure which is mainly mucous is gathered here. The enzymatic activity of the mucosa is reported to be higher in this portion than in the neighboring parts ( $\mathrm{M} \mathrm{cM}$ in $\mathrm{n}$ and $\mathrm{Kugler} 1961$, Cohen 1964).

The duodenal pouch of the elephant as described in this work is believed to be a highly differentiated form of this ampullated portion. Corresponding structures, though not so conspicuous as in the elephant, are known in some other animals which have no gall bladder.

The horse, perhaps the most famous animal without a gall bladder, has a cyst in the duodenal wall connected with the bile and pancreatic ducts. However, this structure is far less differentiated than the pouch of the elephant and scarcely represents a comparable form.

The giraffe is known since $\mathrm{O} w$ e $\mathrm{n}$ (1868) to be lacking in a gall bladder “in normal condition" (cf. W e ber 1904, Siw e 1937). However, the report of $\mathrm{And}$ o (1939) and the recent observation of $\mathrm{K}$ ob a r a and $\mathrm{Kam}$ i y a (1965) have revealed that ther $\theta^{\circ}$ are at least cases which have a well-developed gall bladder. The latter authors have shown that even in those cases a duodenal pouch comparable with that of the horse does exist, which may represent an exception to our rule of alternative occurrence of the gall bladder and of the duodenal pouch.

In the cetacea, another group of animals without gall bladder, K a miya (1962) found a duodenal pouch more conspicuous than that of the horse or giraffe, connected with the bile and pancreatic ducts. It is an elongated sac rich in mucous glands and enclosed either in the tela submucosa (whalebone whales) or in the circular muscle layer of the duodenum (toothed whales).

It is not only in its bigger size that the pouch of the elephant represents a still more differentiated form than that of the cetacea, but also in the following: 1) the musculature of the pouch of the elephant is arranged in four layers, two of which are so specialized as to belong properly to the pouch;2) special sphincter muscles are formed; and 3) large folds are developed in the interior of the pouch. 


\section{Functional anatomy of the pouch.}

On the basis of the findings of this work it is most likely that in the elephant, the extrusion, of the content of the duodenal pouchbile and pancreatic juices together with the mucous product of the pouch itself-is controlled in an exceedingly delicate way in accordance with digestive needs. The elaborate arrangement of muscular layers supports this view. The small muscle connections between different layers may play the role of a conducting system in the contraction of the pouch wall.

When the pouch is not in contraction, the fold inserted into the orifice of the papilla may work as a plug. When the pouch contracts, the muscle in the fold must also be called into contraction. "The plug must thus be retracted from the orifice in order to allow the content to flow out. When the pouch contracts the sphincters at the openings of the bile and pancreatic ducts are believed to contract simultaneously, so that the content of the pouch can not flow backward into the ducts. Thus the structure of the pouch seems quite well accounted for by this explanation of its possible function.

\section{The accessory pancreatic duct and duodenal papilla.}

The reports of previous authors indicate that the Indian elephant possesses both main and accessory pancreatic ducts while the African possesses the former only (cf. Eales 1929). In the six Indian elephants examined in the present study, the accessory duct connected with the accessory papilla duodeni was recognized in all cases except the first one, in which as is written in the Introduction, the duct in question was not found in spite of the existence of a well-formed accessory papilla. As the whole duct-system within the pancreas was dissected out with great care, there seems to remain no possibility that we overlooked the accessory duct in this first case. It seems unlikely, on the other hand, that a duodenal papilla can develop without the formation of a duct connected with it, and therefore we are inclined to suppose that, in this case, the accessory duct may possibly have undergone a secondary disappearance, leaving its papilla which continued to develop as a mucous pouch.

\section{Summary}

In six cases of the Indian elephant the duodenal pouch was examined macro- and microscopically. This ovoid organ buried in the wall of the duodenum is connected with the bile and pancreatic 
ducts on the one hand and opens into the duodenal canal with a big cone-like papilla on the other. The interior of the pouch rich in folds is supplied with a large number of mucous glands. The well developed musculature of the pouch consists of four layers, each of which is connected with the other by a thin muscle bundle (conducting system). At the connection of both the bile and pancreatic ducts with the pouch a strong sphincter is developed, which presumably prevents the reflux of the content of the pouch during its contraction.

The intramural pouch in the duodenum of this animal lacking in a gall bladder seems to represent a highly specialized form of the hepatopancreatic ampullation known in various kinds of mammals.

\section{Acknowledgment}

Sincere thanks are due to Professors Hiromu Outi and $\mathrm{Hiroshi} \mathrm{Hosokawa}$ for their critical reading of the manuscript. Thanks are also due to Dr. J. K o bar a of the Tama Zoological Park and Dr. H. Oikaw a of the Hitachi Zoological Garden for giving the opportunity of dissecting the precious materials.

\section{Literature}

A nd o, B.: On the gall-bladder of the giraffe. Fol. anat. jap. 18: 559-563 (1939).

Bolk, L.: Handbuch der vergleichenden Anatomie der Wirbeltiere. (Siwe, St. A.: Die grossen Drüsen des Darmkanales) $3: 754$, Urban u. Schwarzenberg. Berlin (1937).

Cam per, P.: Kort berigt van de ontleding eens jongen elephants. Vaterlandsche letteroeffeningen. Translated in Camper's Kleinere Schriften. 1:51 and Oeuvres. tom. 1 and 2 (1774) (cited from $\mathrm{Mia} 11$ and $\mathrm{Green}$ wood).

: Description anatomique d'un éléphant mâle. Paris (1802).

Cohen, P.J.: The renewal areas of the common bile duct epithelium in the rat. Anat. Rec. $150:$ 237-242 (1964).

Eales, N.B.: The anatomy of a foetal African elephant, Elephas africanus. Part III. The content of the thorax and abdomen and the skeleton. Trans. Roy. Soc. Edinburgh. 56 : 203-246 (1929).

Kamiya, T.: On the "intramural cystic gland" of the cetacea. Acta anat. nipponica $37: 339-351$ (1962) (in Japanese).

$\mathrm{Kobara}, \mathrm{J}$. and $\mathrm{Kam}$ i $\mathrm{a}, \mathrm{T} .:$ On the gall-bladder of the giraffes. Acta anat. nipponica $40: 161-165$ (1965) (in Japanese).

M c M i n n, R. M. H. and $\mathrm{Kug}$ le r, J.H.: The glands of the bile and pancreatic ducts : autoradiographic and histochemical studies. J. Anat. $95: 1-11$ (1961).

$\mathrm{M}$ i a 11, L.C. and Green wood, F.: The anatomy of the Indian elephant. Part III. J. Anat. Physiol. $13: 17-50$ (1878).

O w e n, R.: On the anatomy of vertebrates. 3. Mammals. 915pp. Longmans and Green. London (1868). 
Shimizu, Y., Fujit a, T., Ka mi ya, T. and Is okawa, S.: Anatomy of a female Indian elephant with special reference to its visceral organs. Acta anat. nipponica 35: 261-301 (1960) (in Japanese).

W e b e r, M.: Die Säugetiere. 3 : 595-598, Fischer, Jena (1904). 